\title{
The Use of Doubly Fed Reluctance Machines for Large Pumps and Wind Turbines
}

\author{
Milutin G. Jovanović, Member, IEEE, Robert E. Betz, Member, IEEE, and Jian Yu
}

\begin{abstract}
Brushless doubly fed induction machines (BDFIMs) have been extensively researched over the last 15 years because of the possibility of using a partially rated inverter in many applications with limited speed variations. However, the special cage rotor construction and substantial rotor losses is one of the key deficiencies of these machines. A similar and extremely interesting machine, the brushless doubly fed reluctance machine (BDFRM), has been largely ignored in comparison. This was mainly due to the fact that reluctance rotor designs were not capable of generating saliency ratios large enough to make the BDFRM competitive with other machines. However, recent developments in reluctance rotors, spurred on by research into synchronous reluctance machines, have resulted in high-saliency-ratio cageless rotors that are economical to build. This, together with the promise of higher efficiency and simpler control compared to the BDFIM, means that further investigation of the BDFRM is warranted. This paper presents a comparative theoretical analysis and aspects of practical implementation of the important control strategies and associated machine performance/inverter size tradeoffs for the BDFRM in the light of its most likely applications-large-pump-type adjustable-speed drives and variable-speed constant-frequency wind power generation systems.
\end{abstract}

Index Terms-Brushless doubly fed machine, electric machine control, reluctance machine, self-cascade machine.

\section{INTRODUCTION}

$\mathbf{T}$ HE brushless doubly fed reluctance machine (BDFRM) belongs to a group of slip power recovery machines together with the classical cascaded induction machine (CIM), the traditional double-excited slip ring induction machine (DESRIM) and the brushless doubly fed induction machine (BDFIM). ${ }^{1}$ A common property of all the machines from this group is that if the operational speed range is restricted a converter, which is normally supplying one of the windings, can be fractionally rated the specific rating being determined

Paper IPCSD 02-057, presented at the 2001 Industry Applications Society Annual Meeting, Chicago, IL, September 30-October 5, and approved for publication in the IEEE TRANSACTIONS ON INDUSTRY APPLICATIONS by the Electric Machines Committee of the IEEE Industry Applications Society. Manuscript submitted for review August 1, 2001 and released for publication August 21, 2002. This work was supported by the Engineering and Physical Sciences Research Council under Grant GR/N34550 and by the Australian Research Council.

M. G. Jovanović and J. Yu are with the School of Engineering and Technology, Northumbria University, Newcastle upon Tyne NE1 8ST, U.K. (e-mail: milutin.jovanovic@unn.ac.uk; jian.yu@unn.ac.uk).

R. E. Betz is with the School of Electrical Engineering and Computer Science, University of Newcastle, Callaghan, NSW 2308, Australia (e-mail: reb@ee.newcastle.edu.au).

Digital Object Identifier 10.1109/TIA.2002.804749

${ }^{1} \mathrm{~A}$ good review of the BDFRM/IM historical evolution is presented in [1]. by the magnitude of the speed range around a "synchronous" speed. ${ }^{2}$ In order to achieve the enhanced control and operational mode flexibility and improved power quality, a bidirectional PWM converter should be used. The cost, switching losses, and line harmonic content of this configuration would be substantially reduced by the lower kVA requirement. As far as the machine is concerned, it turns out that with the same torque as an induction machine or an equivalent synchronous reluctance machine (Syncrel), a larger BDFIM/RM is required [2]. Therefore, the use of a BDFIM/RM allows a tradeoff between the size of the converter and machine. For classes of large limited-range variable-speed systems, ${ }^{3}$ the overall system cost could be significantly lower compared to applications with fully rated converters despite the somewhat increased cost of the machine itself $^{4}$ [1]. The previous advantages can be also accomplished using static Kramer or Scherbius cascades based on a DESRIM. However, the BDFRM/IM's brushless and, therefore, maintenance-free, structure offers improved reliability to these systems. For these reasons, BDFRM/IM-based drive technology may be an ideal brushless solution for such areas as variable-speed constant-frequency (VSCF) hydro and wind power generation [3]-[5], commercial heating, ventilation, and air conditioning (HVAC), large pump-type drives (pumps [6], [7], fans, blowers, compressors, etc.), as well as turbo machinery (where the rugged nature of the rotor and the synchronous machine mode of operation can be exploited [8]).

The BDFIM/RM has two stator windings of different pole numbers and generally different applied frequencies (Fig. 1) - the primary (power) winding is grid connected and the secondary (control) winding is converter fed. Magnetic coupling between the windings, a prerequisite for torque to be produced from the machines, is provided via the rotor having half the total number of stator poles. ${ }^{5}$ In the BDFIM case, the rotor is of special cage construction composed of nested loops [9], whereas the BDFRM can use any of the Syncrel's rotor designs. In many respects, the BDFRM and the BDFIM are obviously similar, however, the BDFRM has the following important advantages.

\footnotetext{
${ }^{2}$ This is half the speed of a conventional synchronous machine having the same number of rotor poles. It corresponds to the situation when the inverter-fed winding of the BDFRM/IM is de supplied.

${ }^{3}$ For a speed range of $2: 1$, which is typical for pumps and wind turbines, the converter real power rating can be reduced to about $25 \%$ of the machine rating.

${ }^{4}$ Note that, in small-power applications, the cost benefits would not be that pronounced due to relatively low market prices of associated power electronic hardware.

${ }^{5}$ Unlike a conventional machine, the BDFRM/IM's rotor pole number can be odd (for four/two-pole stator windings). The most common design reported in the literature is however with a six/two-pole stator and a four-pole rotor.
} 


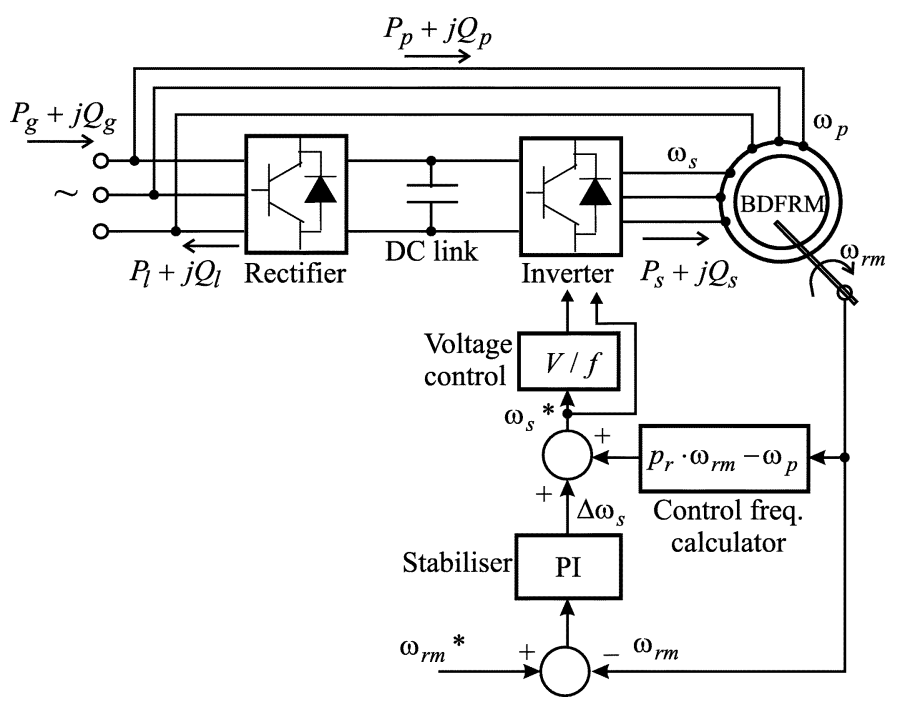

Fig. 1. Schematic of a BDFRM-based drive system with closed-loop scalar control.

- It is potentially more efficient" (since the "cold" rotor losses are much smaller than with the BDFIM), and should be able to operate at higher speeds because the cageless rotor can be more robustly constructed.

- It is considerably easier to model and control as the BDFIM has an additional winding on the rotor.

- In contrast to the BDFIM, the BDFRM allows inherently decoupled control of torque and primary reactive power (so does the DESRIM) which further facilitates its vector control schemes [11]. For the BDFIM, complicated decoupling algorithms are required to achieve the same objective [12].

- It can operate stably and reliably over the entire speed range (at sub and supersynchronous speeds) in both motoring and generating modes. The BDFIM, on the other hand, has stability problems around the zero-torque operating point at synchronous speed of the grid-connected winding field [13].

This paper will, consequently, limit its scope to the BDFRM.

The primary target applications of the BDFRM are envisaged to be large pumps [6] and VSCF wind turbine generators [3]. In these systems, the shaft power is approximately varying with the speed cube. This paper will attempt to answer how the BDFRM should be controlled to achieve optimum theoretical performance under this condition. Control properties to be investigated include: maximum torque per inverter ampere, maximum power factor (at the mains supply side), and minimum inverter VA for a given torque. Tradeoffs associated with these control strategies shall be examined, and correlations of the BDFRM parameters with those of its single-fed counterpart, the Syncrel, shall be made where appropriate. The machine ability of primary reactive power control for minimum copper losses in the machine shall be also considered. Basic principles of scalar and vector control of the machine will be also established. Most of this analysis is carried out using independent

6It has been experimentally verified in [10] that this is the case if the machines are inverter driven but not for dead online operation. normalized modeling techniques for an ideal machine (no saturation and with sinusoidal windings).

\section{MAIN APPLICATIONS}

This section is a brief review of the above-mentioned most likely applications of the BDFRM-wind turbines and large pumps.

The majority of wind turbine installations use grid-connected cage induction generators because they are relatively cheap, reliable, and reasonably efficient. The generator is normally mechanically coupled to a turbine rotor shaft through a step-up gearbox. This configuration is of fixed-speed type since the generator is operated slightly above the synchronous speed in order to have small absolute slips and, therefore, better efficiency. The most serious limitation of such a system is that the available wind power is not adequately utilized and the maximum energy extraction can be achieved only at a single wind speed (or in a very narrow range). It is mainly for this reason that VSCF generation (VSCFG) has been recently becoming very popular.

Apart from the possibility of maximum wind power capture at all allowable wind speeds, which is certainly the main virtue of VSCFG, variable-speed turbines have many other advantages over fixed-speed ones: considerably improved power quality, reduced mechanical stresses on a drive train, and lower noise impact at low wind speeds (more details about this and related issues can be found in [4]). However, if the generator is interfaced to the supply grid using fully rated power electronics, these advantages can be offset by the high system cost. The use of BDFRM with a small bidirectional pulsewidth modulation (PWM) converter would be, therefore, a cost-effective and reliable brushless ${ }^{7}$ design solution for VSCFG. Furthermore, an additional degree of control freedom relative to singly fed machines and consequent possibility of reactive power compensation (i.e., power-factor regulation) and/or efficiency optimization [4], [5] in addition to torque (real power) control, are undoubtedly the other attractive BDFRM features that can be of particular interest to this and similar applications.

The maximum power output of a typical wind turbine can be represented as [4], [5]

$$
P_{t_{\max }}=\frac{1}{8} \cdot \pi \cdot \rho \cdot C_{p}\left(\lambda_{\mathrm{opt}}, \beta\right) \cdot D^{2} \cdot v^{3}
$$

where $\rho$ is the air density (specific mass), $C_{p}$ is the power coefficient (i.e., turbine efficiency), $\lambda_{\text {opt }}=D \omega_{t} / 2 v$ is the optimum tip speed ratio ( $\omega_{t}$ is the turbine rotor angular velocity), $\beta$ is the blade pitch, $D$ is the blade (rotor) diameter, and $v$ is the wind speed. Therefore, by varying the turbine speed so that the tip speed ratio is kept constant at its optimum value for a given wind speed in the base speed region (between the minimum "cut-in" speed and the rated speed) the turbine efficiency is then maximized. At higher wind speeds, the power must be restricted to a rated level to avoid generator overloading.

\footnotetext{
${ }^{7}$ In this respect, the BDFRM is superior to a wound-rotor synchronous machine which can also serve as a wind power generator (multipole designs are often used as direct, i.e., gearless drives).
} 
In large pump applications, the BDFRM-based adjustablespeed drive can be used instead of a wound-rotor induction machine as a maintenance-free brushless alternative [6]. With a partially rated converter, the payback periods can be substantially reduced, which, given all the performance benefits of variable-speed pumping in terms of energy savings, would make the BDFRM preferable to uncontrolled constant-speed induction machines in these systems.

\section{PRELIMINARIES}

Before considering the control-related issues in detail, it may be beneficial to briefly review the fundamental properties and key space-vector equations of the BDFRM. It is beyond the scope of this paper to develop the complete dynamic model of the BDFRM, and relevant expressions will simply be stated [14], [15]

$$
\begin{aligned}
& \underline{u}_{p}=R_{p} \underline{i}_{p}+\frac{d \underline{\lambda}_{p}}{d t}+j \omega_{p} \underline{\lambda}_{p} \\
& \underline{u}_{s}=R_{s} \underline{i}_{s}+\frac{d \underline{\lambda}_{s}}{d t}+j\left(\omega_{r}-\omega_{p}\right) \underline{\lambda}_{s} \\
& \underline{\lambda}_{p}=L_{p} \underline{i}_{p}+L_{p s} \underline{i}_{s}^{*}=\lambda_{p}\left(\lambda_{p q}=0\right) \\
& \underline{\lambda}_{s}=L_{s} \underline{i}_{s}+L_{p s} \underline{i}_{p}^{*}
\end{aligned}
$$

where $L_{p, s, p s}$ are the constant self and mutual three-phase inductances of the primary and secondary windings (their definitions can be found in [2] and [16]). In steady state, the machine develops useful torque if [15], [17]

$$
\omega_{r}=p_{r} \omega_{r m}=\omega_{p}+\omega_{s} \Longleftrightarrow \theta_{r_{f}}=p_{r} \theta_{r m_{f}}=\theta_{p_{f}}+\theta_{s_{f}}
$$

where $\omega_{r m}=d \theta_{r m_{f}} / d t$ is the rotor mechanical angular velocity (radians per second), $p_{r}$ is the number of rotor poles equal to the sum of the windings pole pairs (not poles), $\omega_{p, s}=$ $d \theta_{p, s} / d t$ are the applied frequencies (radians per second) to the windings, and $\theta_{r, p, s_{f}}$ are the reference frame (not vectors) angular positions relative to a stationary $d-q$ frame as illustrated in Fig. 2 (the rotor frame not shown). The above reference frame relationship serves as a basis for field-oriented control of the machine as will be shown in Sections IV-VII.

Remark 1: One of the most distinguishing features of the space-vector model for the BDFRM is that the primary (subscript " $p$ ") and secondary (subscript " $s$ ") equations are in two different reference frames - one rotating at $\omega_{p}$ and "naturally" chosen to be aligned with the primary flux $\lambda_{p}$ (as this is of fixed frequency and approximately constant magnitude due to the winding grid connection) and the other rotating at $\omega_{r}-\omega_{p}=\omega_{s}$ (Fig. 2).

Remark 2: The $\underline{i}_{s}^{*}$ and $\underline{i}_{p}^{*}$ terms in (4) and (5) are the complex conjugates of the "coupled" current vectors from the secondary to the primary winding and vice versa and they rotate at $\omega_{p}$ and $\omega_{s}$, respectively. These two terms are the original current vectors referred to their complementary winding side but in a frequency (not traditional turns ratio) sense. This frequency transformation results from the modulation process (similar to that in a communication mixer) of the stator magnetomotive force (MMF) waveforms via the rotor, and represents the basic mechanism behind magnetic coupling and torque production in the machine [17].

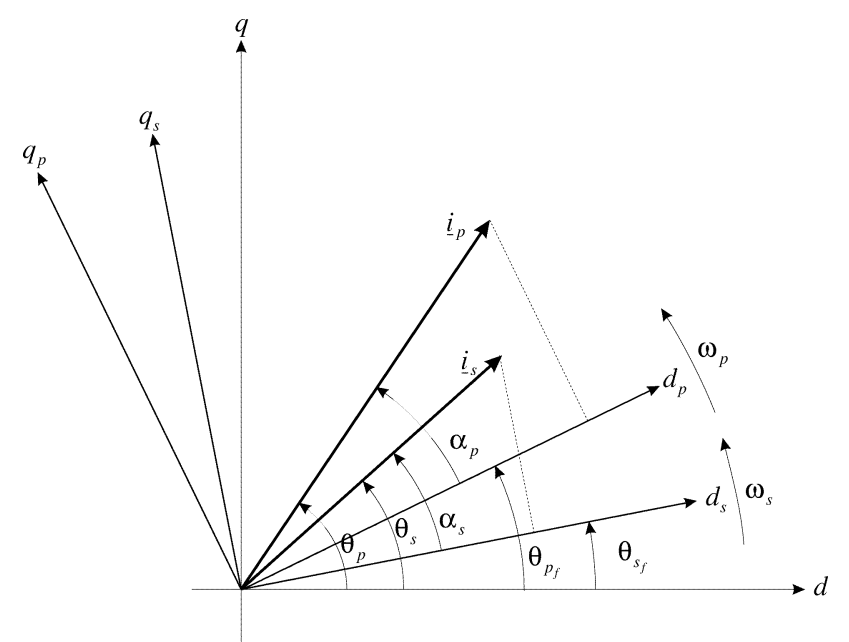

Fig. 2. Reference frames and current angles for BDFRM modeling.

Remark 3: It is interesting that, despite the existence of two separate frames and the fundamentally different operating principles, the above equations are virtually identical in form to those for the DESRIM. The fact that there is such a close model similarity of the two machines means that the existing control schemes for the DESRIM can be essentially applied to the BDFRM [18], [19].

Remark 4: It should be noted that the dynamics of the BDFRM are not as fast as those of the DESRIM because of the relatively high leakage inductances of the BDFRM. This limitation is not that important for the applications considered here (especially not for pumps) as very quick transient response is not required.

Remark 5: From a control viewpoint, another important implication of the above current mapping is that the secondary to primary flux coupling term $L_{p s} \underline{i}_{s}^{*}$ in (4) can be directly controlled by the secondary currents supplied from an inverter. How this is achieved is discussed next.

\section{CONTROL ASPECTS}

\section{A. Relevant Expressions}

In order to make the development of analytical expressions of importance for control feasible, the machine is assumed lossless. This approximation should have little effect on the accuracy of the analysis to be performed in Sections V-VII. In addition, motoring convention has been adopted as a reference.

Substituting for (2)-(5) into the general expression for complex electrical power- $P_{p}+j Q_{p}=3 / 2\left(\underline{u}_{p} \underline{i}_{p}^{*}+\underline{u}_{s} \underline{i}_{s}^{*}\right)$, one can derive the normalized expressions ${ }^{8}$ in a form suitable for primary-flux-oriented control of the BDFRM

$$
\begin{aligned}
& P_{p n}=\frac{1}{2} T_{n}=\frac{L_{p s}}{L_{p}} i_{s n} \sin \alpha_{s} \\
& P_{s n}=\frac{\omega_{s n}}{2} T_{n}=\omega_{s n} P_{p n}=-s P_{p n}=\frac{\omega_{s n}}{1+\omega_{s n}} P_{n}
\end{aligned}
$$

${ }^{8}$ The base values used for normalizations are [14]

$$
T_{B}=\frac{3}{4} p_{r} \frac{\lambda_{p}^{2}}{L_{p}} ; \quad P_{B}=\frac{2 \omega_{B}}{p_{r}} T_{B} ; \quad i_{B}=\frac{\lambda_{B}}{L_{B}}=\frac{\lambda_{p}}{L_{p}}
$$

where $V_{B}$ and $\omega_{B}=\omega_{p}=2 \pi f_{B}$ are the grid supply voltage and frequency. 


$$
\begin{aligned}
& P_{n}=P_{p n}+P_{s n}=\frac{1+\omega_{s n}}{2} T_{n}=\omega_{r n} T_{n} \\
& T_{n}=2 \frac{L_{p s}}{L_{p}} i_{s q n}=2 \zeta i_{s n} \sin \alpha_{s} \\
& Q_{p n}=1-\zeta i_{s d n}=1-\frac{T_{n}}{2 \tan \alpha_{s}} \\
& Q_{s n}=\frac{\omega_{s n} T_{n}}{4 \tan ^{2} \alpha_{s}} \\
& \times\left[T_{n}\left(\frac{1}{k_{p s}^{2}}-1\right)\left(\tan ^{2} \alpha_{s}+1\right)+2 \tan \alpha_{s}\right] \\
& i_{p n}=\frac{\sin \alpha_{s}}{\sin \left(\alpha_{p}+\alpha_{s}\right)} \\
& =\frac{\sqrt{\left(2 \tan \alpha_{s}-T_{n}\right)^{2}+T_{n}^{2} \tan ^{2} \alpha_{s}}}{2 \tan \alpha_{s}} \\
& i_{s n}=\frac{\sin \alpha_{p}}{\zeta \sin \left(\alpha_{p}+\alpha_{s}\right)}=\frac{T_{n} \sqrt{1+\tan ^{2} \alpha_{s}}}{2 \zeta \tan \alpha_{s}} \\
& \left.\begin{array}{c}
\lambda_{p n}=i_{p d n}+\zeta i_{s d n}=1 \\
i_{p q n}-\zeta i_{s q n}=0
\end{array}\right\} \Leftrightarrow \tan \alpha_{p} \\
& =\frac{T_{n} \tan \alpha_{s}}{2 \tan \alpha_{s}-T_{n}}
\end{aligned}
$$

where $\zeta=L_{p s} / L_{p}, k_{p s}=L_{p s} / \sqrt{L_{p} L_{s}}$ is the coupling coefficient between the windings, and (15) represents the fundamental relationship (this corresponds to the primary flux/reference frame alignment conditions contained in (4)) between the primary and secondary current angles $\alpha_{p, s}$ defined as shown in Fig. $2\left(0 \leq \alpha_{s} \leq \pi\right.$ for motoring and $\pi \leq \alpha_{s} \leq 2 \pi$ for generating). The previous equations are developed in terms of the secondary current vector magnitude and angle (as the secondary current $d_{s} q_{s}$ components are directly controllable via the inverter) for a given torque value.

\section{B. Vector Control}

The BDFRM can be configured into a drive system ${ }^{9}$ of the form of Fig. 3 employing vector control techniques based on the above expressions [11]. It should be noted that the reference frame position for the secondary winding $\left(\theta_{s_{f}}\right)$ can be determined using the primary frame position $\theta_{p_{f}}$ (both the primary flux angle and magnitude can be estimated from the measured grid voltages $\left.{ }^{10}\right)$, rotor position measurement $\theta_{r m_{f}}$, and (6). Once $\theta_{s_{f}}$ is known one can implement current control of the secondary $d_{s} q_{s}$ components (and, thus, torque and primary reactive power) in a conventional way as shown in the same figure.

The desired values of torque and reactive power $\left(T_{e}^{*}\right.$ and $\left.Q_{p}^{*}\right)$ in Fig. 3, corresponding to (10) and (11), respectively, depend on the control strategy to be implemented (related aspects are

${ }^{9}$ Fig. 3 does not show the circuitry required for starting. If a partially rated inverter is used then an auxiliary contactor is usually needed to short the secondary terminals directly or through external resistors. This allows the BDFRM to start as an induction machine. Once the machine is near the synchronous speed the contactors are opened and the inverter is connected.

${ }^{10}$ Estimation errors can occur due to the presence of the primary winding resistance, but in most cases these are negligible because of the dominant back-EMF effect.

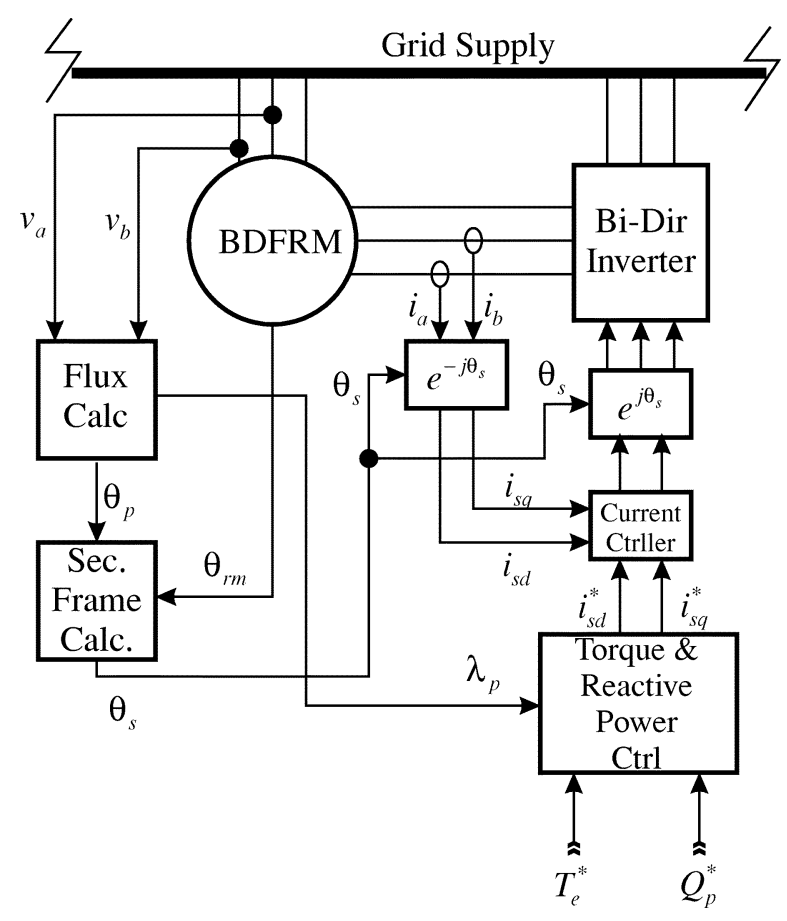

Fig. 3. Simplified block diagram of a BDFRM control system.

discussed in the following). In the case of a wind turbine generator, according to (1), the torque command in the base speed region can be formulated as

$$
T_{e}^{*}=\frac{P_{t_{\max }}}{\omega_{r m}}=\frac{\pi \cdot \rho \cdot C_{p_{\max }} \cdot D^{5}}{\lambda_{\mathrm{opt}}^{3} \cdot g^{3}} \cdot \omega_{r m}^{2}=C_{\mathrm{bdfrm}} \cdot \omega_{r m}^{2}
$$

where $g=\omega_{r m} / \omega_{t}$ is the gear ratio, $C_{\mathrm{bdfrm}}$ should be known for a particular turbine, and the remaining parameters have already been defined. For vector-controlled drives, the torque set point is the output of a speed loop.

\section{Scalar Control}

In pump-type applications [6], simple scalar control with low-cost microprocessor implementation appears to be an appropriate solution as high dynamic performance is not required and speed variations are relatively limited. Some preliminary results generated using Simulink, illustrating the machine response to step changes of speed and load torque under openand closed-loop constant V/f control ${ }^{11}$ (Fig. 1), are presented in Figs. 4 and 5, respectively. A six/two-pole machine (whose data have been taken from [11] for simulation purposes) has been started with the shorted secondary winding to a speed close to synchronous (750 r/min) when the inverter is connected and the control enabled. It can be seen that the machine performance is much better with the lower speed oscillations and faster response under closed-loop control as expected. This should be attributed to the smoothing action of the PI controller (the "stabiliser" block in Fig. 1). The open-loop algorithm has been experiencing stability problems in case of larger step changes of command secondary frequency $\left(\omega_{s}^{*}\right)$.

\footnotetext{
${ }^{11}$ Keeping the secondary flux at its approximately rated value is by no means optimal for the BDFRM. This approach has been chosen simply for testing the control schemes.
} 


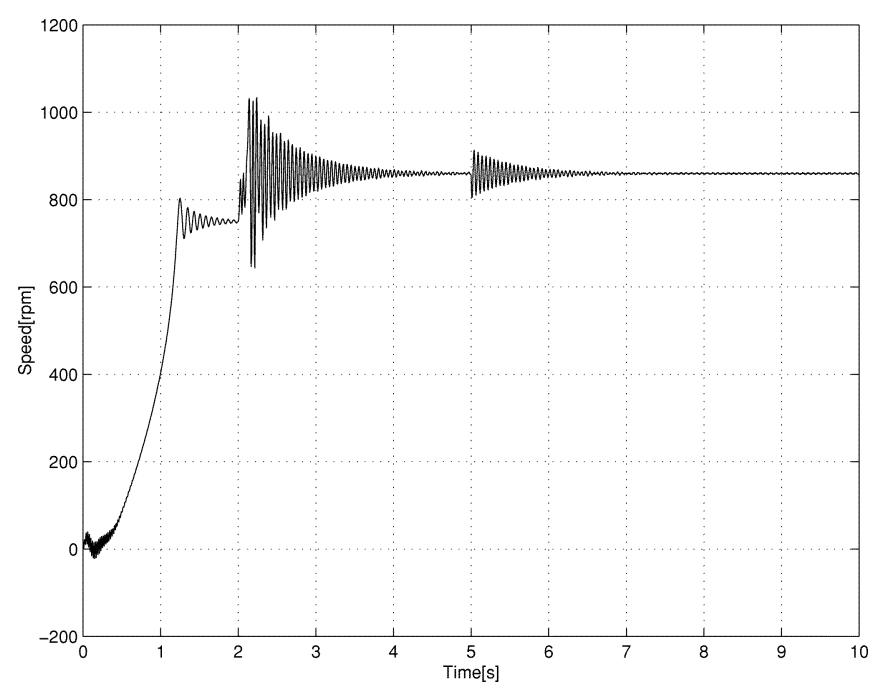

Fig. 4. BDFRM response under open-loop V/f speed control (speed step change at $2 \mathrm{~s}$ and load torque step change at $5 \mathrm{~s}$ ).

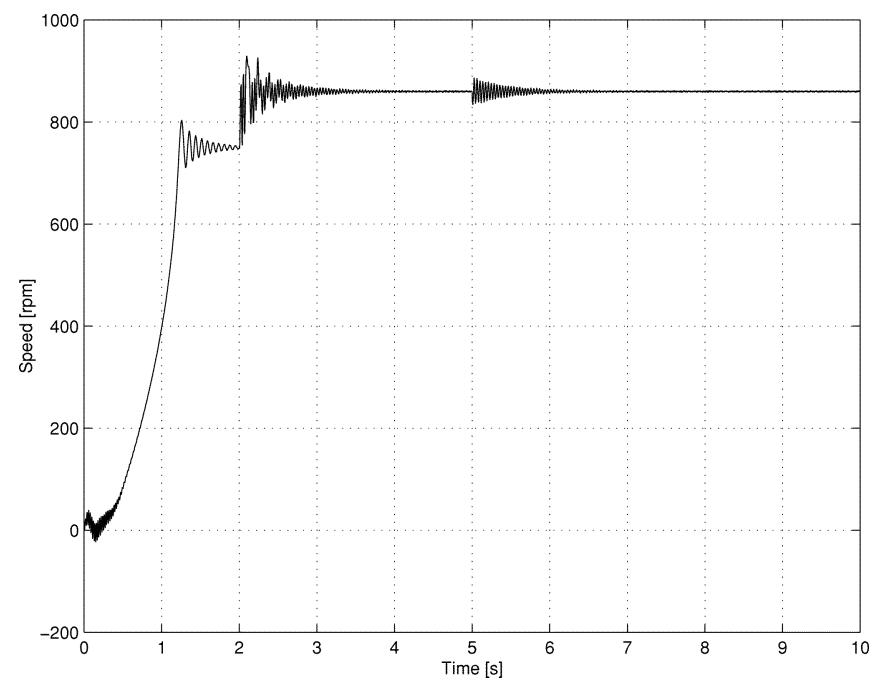

Fig. 5. BDFRM speed with closed-loop V/f control (speed step change at $2 \mathrm{~s}$ followed by load torque step change at $5 \mathrm{~s}$ ).

\section{OPERATING MODES}

As a member of the doubly fed family of machines, one of the BDFRM's main virtues is the operational flexibility. The secondary power expression (8) indicates the BDFRM's ability to emulate the DESRIM in slip-power recovery systems as the supply inverter only has to handle the amount of real power proportional to the degree of slip $s=-\omega_{s} / \omega_{p}=-\omega_{s n}$. Therefore, if the machine was required to operate at small absolute slips, i.e., in a narrow speed range around the synchronous speed $\omega_{\text {syn }}=\omega_{p} / p_{r}=0.5$-pu (which is, for instance, the situation in pump drives [6] and wind turbines [4]), then a fractionally rated inverter would be sufficient (Fig. 6). From Fig. 6 one can also see that at supersynchronous speeds $\left(\omega_{r n}>0.5\right)$ the power flow in both windings is to the machine when operated as a motor (and to the grid for a generator). At 1-pu speed, when the secondary is supplied with the mains frequency, the two windings evenly share the machine real power loading and the inverter has to handle half the machine power in this case.

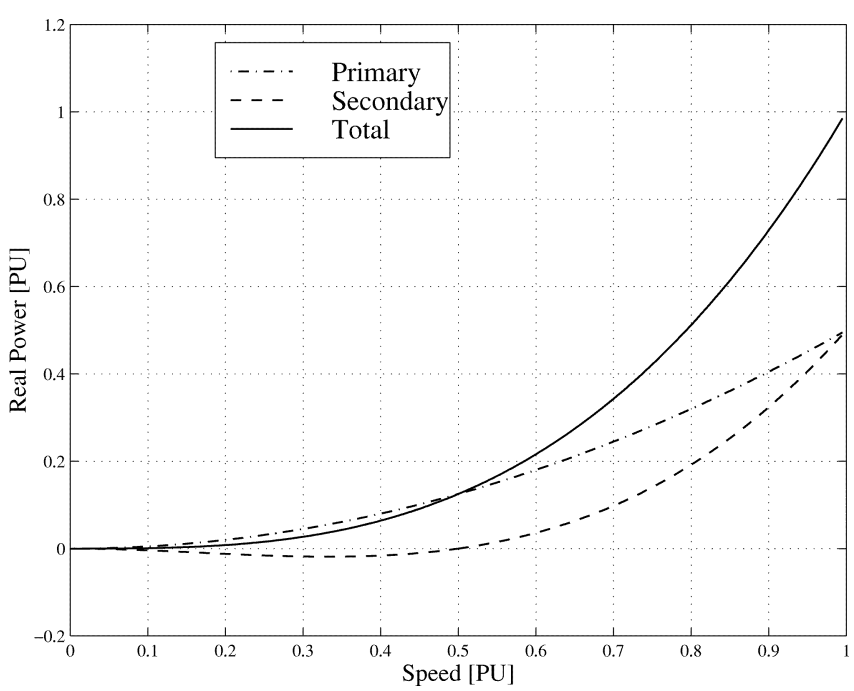

Fig. 6. Real power share between the BDFRM windings operating as a motor at $T_{n}=\omega_{r n}^{2}$.

At synchronous speed $\left(\omega_{s n}=s=0\right)$ the secondary is dc fed and the BDFRM behaves as a classical field-controlled $2 p_{r}$-pole synchronous turbo machine with $\alpha_{s}$ effectively becoming the torque angle [8]. The inverter does not contribute to any power under this condition (Fig. 6) but only covers the secondary resistive losses. In this operating mode, the BDFRM could be used as a high-requency alternator in the automotive industry where, apart from the low cost, its terminal voltage regulation property would be an additional advantage over permanent-magnet machines. Furthermore, supplying the primary from another converter, a brushless variable-speed synchronous motor suitable for high-speed field-weakened traction and spindle applications could be realized, but at the expense of a higher cost.

If $\omega_{s n}<0$ (which means the opposite phase sequence of the secondary to the primary), then $P_{s n}<0$ as follows from (8) and the primary power being taken from the grid is circulating through the machine to be returned back to the supply via the secondary winding (for a generator, the real power flow is completely reversed). In this operating region, the machine is running at subsynchronous speeds $\left(\omega_{r n}<0.5\right)$ and a fully regenerative inverter would be required for sustained operation. Under this condition, the line-side converter should be appropriately controlled (not shown in Fig. 3) to maintain real power balance, thus preserving the dc-link voltage stability (it acts as a dc voltage regulator in this case) [20]. However, if this mode is only used for starting (the machine is at standstill for unity slip, i.e., $s=-\omega_{s n}=1$ ) then resistive dumping could be an option. A more common solution is short the secondary winding, either directly or via external resistors, and start the BDFRM as an induction machine. The possibility of induction motor operation is an important "fail-safe" mode of the BDFRM in case of inverter failure.

\section{OPtimal CONTROL STRATEGIES}

This section is concerned with different control methodologies for the BDFRM having a square torque-speed characteristic (in normalized terms $T_{n}=\omega_{r n}^{2}$ ). The plots to be presented 


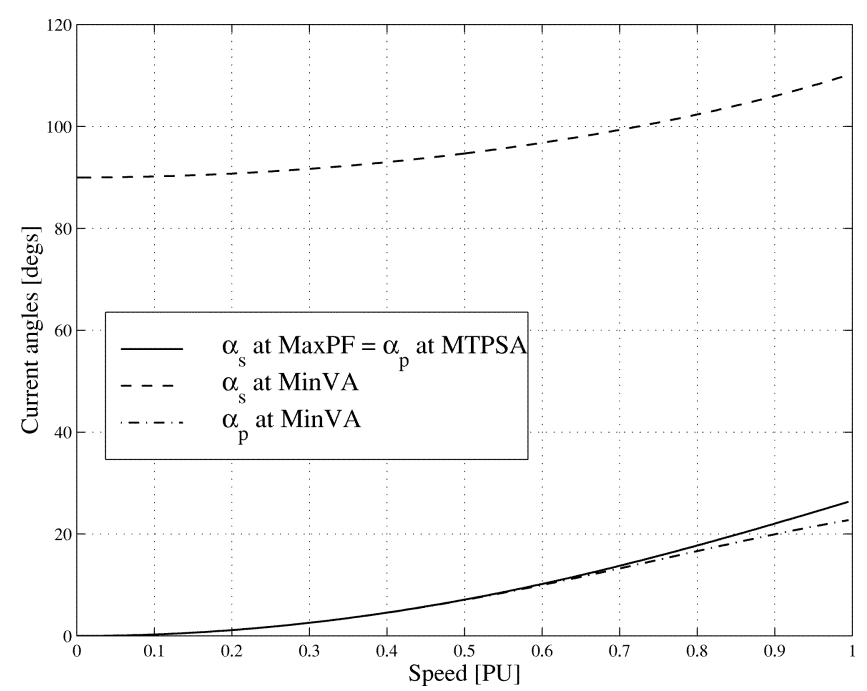

Fig. 7. Current angles for different control strategies and $T_{n}=\omega_{r n}^{2}$.

in the following correspond to the motoring mode (for generating they are very similar) and have been generated assuming that the secondary winding has twice the number of primary effective phase turns per pole $\left(n_{s}=2 n_{p}\right)$ which is equivalent to $L_{s}=4 L_{p}$, i.e., $k_{p s}=L_{p s} / \sqrt{L_{p} L_{s}}=\zeta / 2=7 / 9$ (the BDFRM rotor, when used in a Syncrel, has the typical saliency ratio of $\xi=8$ ) [2], [16]. It has been shown in [2] that under these conditions the BDFRM is a larger machine than the Syncrel for a given torque.

\section{A. Maximum Power Factor}

Equations (10) and (11) demonstrate one of the most salient properties of the BDFRM - the inherently decoupled control of torque and primary reactive power. The torque is controlled via the $q_{s}$-axis secondary current (as $\lambda_{p}=$ const.) $i_{s q n}$ and the reactive power through the $d_{s}$-axis component $i_{s d n}$. This is a significant control simplification as there is no need for special decoupling algorithms that are normally present with vector control techniques for other more conventional machines (except for the DESRIM having the same advantage [20]).

Therefore, regardless of the BDFRM's constant primary flux operation, one can regulate torque and primary power factor simultaneously and independently (see Fig. 3) [11] this being clearly impossible with single-excited machines. For a given torque, the maximum power factor (MaxPF) i.e., $Q_{p n}=0$ is obtained at the secondary current angle of

$$
\alpha_{s_{\mathrm{MaxPF}}}=\tan ^{-1} \frac{T_{n}}{2}
$$

One can easily conclude from (15) that the corresponding primary current vector is in quadrature with the respective flux (remember that this lies along the $d_{p}$ axis in Fig. 2), i.e., $\alpha_{p_{\mathrm{MaxPF}}}=\pi / 2$ as expected for zero reactive power condition. The secondary winding is entirely responsible for the machine magnetization and $\alpha_{s}$ angles are small in this case (Fig. 7). The inverter current rating should be increased appropriately (more than three times for the machine operation around the

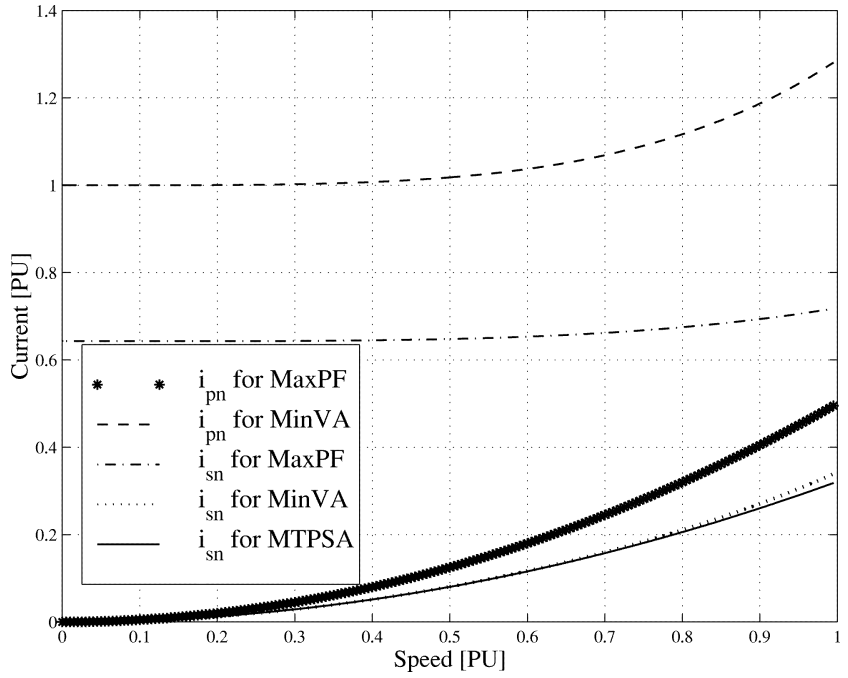

Fig. 8. Optimal currents under pump loading conditions.

synchronous speed) if this control strategy is desired as shown in Fig. 8.

It is also notable from Fig. 8 that under MaxPF conditions, due to $\lambda_{p}=$ const and dominant reactive ( $d$ axis) component, the secondary current $\left(i_{s n}\right)$ variations are insignificant especially at lower speeds (and torques) where $i_{s n}$ is almost constant. The primary current, on the other hand, is low as this is nothing else but a coupled torque producing $i_{s q n}$ current since $i_{p d n}=0$.

If supplied from a dual-bridge PWM converter, the BDFRM (as well as the DESRIM) has another feature that can be of extreme importance for the considered applications-it can operate as a reactive power compensator with minimum copper losses [20]. It has been demonstrated in the authors' recent work [16] that it is possible to minimize total copper losses in the machine (and thus further improve its efficiency) for a given torque by controlling $i_{s d n}$ and, hence, $Q_{p n}$ as this is $i_{s d n}$ dependent considering (11). The unity overall power-factor control is achieved by supplying the reactive power required by the primary not from the grid but using the PWM rectifier $\left(Q_{g}=0\right.$ and $Q_{l}=Q_{p}$ in Fig. 1).

\section{B. Maximum Torque Per Inverter Ampere}

In terms of reducing the converter size needed to supply the machine, another performance index of interest to be optimized is the secondary winding current. The maximum torque per secondary ampere (MTPSA) strategy should provide the minimum inverter current (Fig. 8) for a given torque. As indicated by (10), the optimum secondary current angle for this condition to be satisfied is $\alpha_{s_{\mathrm{MTPSA}}}=\pi / 2$

The same equation also points out the general improvement of torque per ampere with increasing the $\zeta=L_{p s} / L_{p}$ ratio. This suggests that it would be desirable to design a machine with both $n_{s} / n_{p}$ and the rotor saliency ratio $\left(\xi=L_{d} / L_{q}\right)$ as higher as possible [2]. It has been shown in [2] that with $n_{s}=n_{p}$, the same amount of active material and equal copper losses the BDFRM has inferior MTPSA compared to the Syncrel. However, due to the lower inductances the BDFRM can attain much higher speeds and develop more power using the same inverter 


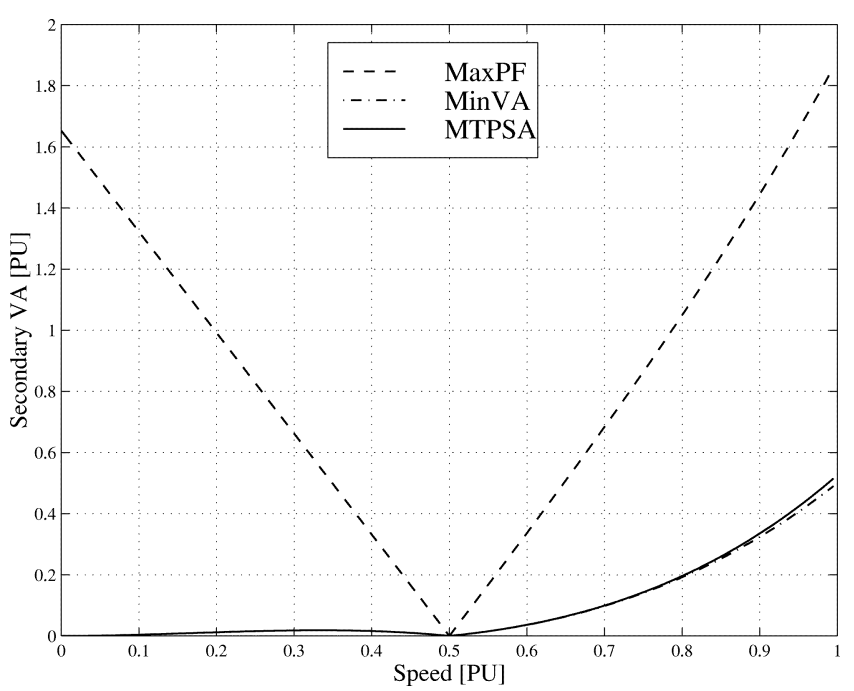

Fig. 9. Inverter VA requirements for various control strategies.

than the Syncrel. Its maximum power output per inverter ampere and efficiency are consequently better under the above conditions.

\section{Minimum Inverter VA}

This control strategy allows one to minimize the inverter size required for a machine. The minimum inverter VA (MinVA) for a lossless machine occurs for $Q_{s n}=0$, i.e., at the unity secondary power factor and the control angle of

$$
\alpha_{s_{\mathrm{MinVA}}}=\tan ^{-1} \frac{-\sqrt{1-T_{n}^{2}\left(\frac{1}{k_{p s}^{2}}-1\right)^{2}}-1}{T_{n}\left(\frac{1}{k_{p s}^{2}}-1\right)}>\frac{\pi}{2} .
$$

Note that the MinVA angles, though close, are greater than $\pi / 2$ (as these are defined with respect to the primary and not secondary-flux-oriented reference frame) indicating the demagnetizing effect of $i_{s n}$ on the primary flux (Fig. 7). A large flux-producing primary current is, therefore, required to maintain $\lambda_{p}$ constant (Fig. 8) which conforms with the lower values of $\alpha_{p}$ angles in Fig. 7. It can be seen from Fig. 8 that the MinVA primary current waveform is quite similar in shape to that of $i_{s n}$ under MaxPF conditions.

Another important observation from (12) is that the better magnetic coupling between the windings (the higher $\left.k_{p s}\right)$ the lower both reactive power $\left(Q_{s n}\right)$ and inverter VA $\left(=\sqrt{P_{s n}^{2}+Q_{s n}^{2}}\right)$. Unfortunately, the BDFRM is not a good machine in this respect because of the unusual operating principle where one of the flux side bands is torque producing and the main fundamental flux and other sideband are leakage components [17]. As a consequence, even with an axially laminated rotor which allows high saliency ratios and coupling coefficients [21], $k_{p s}$ values are relatively modest ( 0.78 under the assumptions adopted) resulting in compromised torque performance for the machine [2].

The MinVA and MTPSA control strategies are closely related and the corresponding set points virtually coincide over the entire speed range (Figs. 7-10). One can see from Fig. 10 that the MTPSA secondary power factor $\left(\cos \phi_{s}\right)$ is near unity

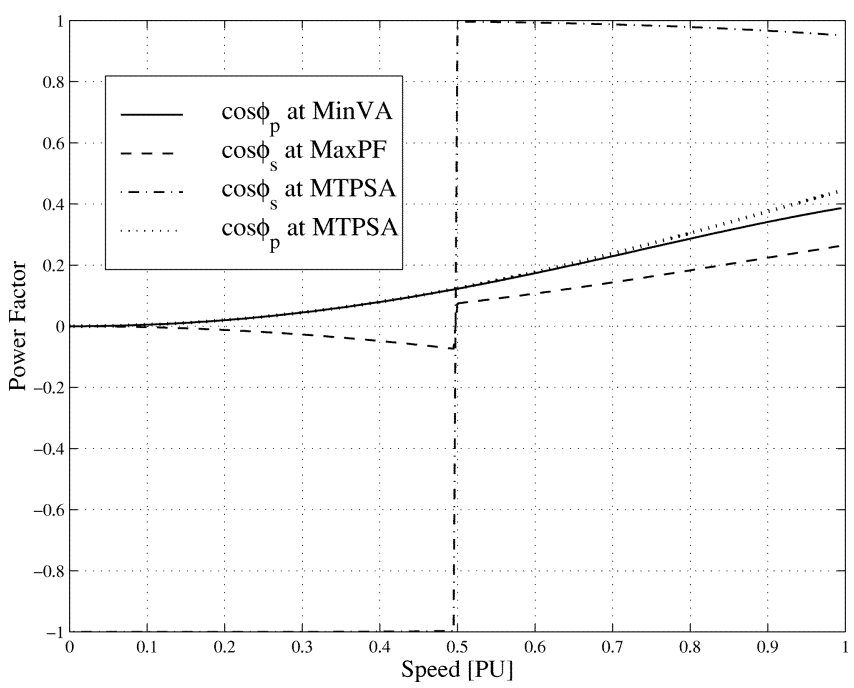

Fig. 10. Power-factor performance for control strategies investigated.

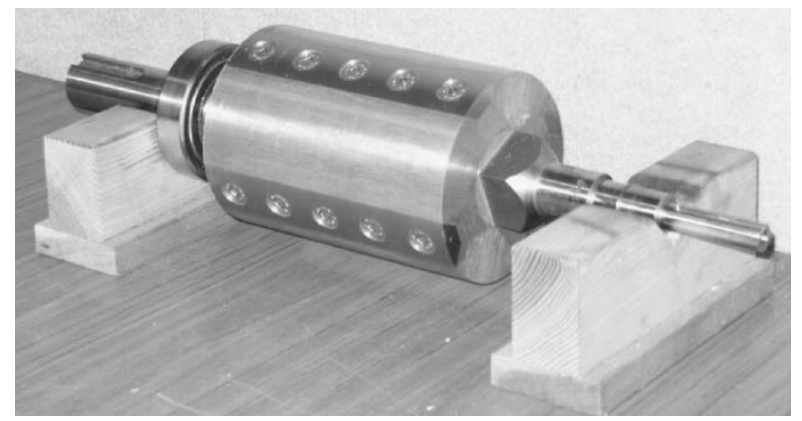

Fig. 11. Axially laminated rotor of the BDFRM.

the change of sign occuring at synchronous speed $(0.5 \mathrm{pu})$ as a reflection of the secondary real power profile in Fig. 6. A reversible power flow at the secondary winding side allows the BDFRM operation at both sub and supersynchronous speeds in motoring as well as in generating mode. The actual operating regime of the machine is determined by the electrical power flow in the primary winding.

Notice from Fig. 9 that for the MaxPF strategy the secondary $\mathrm{kVA}$ needed is much larger compared to the other strategies, which is consistent with the results in Fig. 8. The corresponding power factor is lagging as the inverter is supplying the reactive power for the machine magnetization under the MaxPF conditions.

\section{EXPERIMENTAL RESULTS}

At this stage, the experimental results have not been compiled. Therefore this section will outline the progress made so far toward the generation of these results.

A BDFRM prototype, based on a $10-\mathrm{kW}$ induction machine frame and an axially laminated four-pole reluctance rotor, is being constructed. The rotor is complete, and appears in Fig. 11. The parallel path windings have been designed, and are being checked via a finite-element (FE) analysis. This will allow the torque of the machine to be calculated, and more importantly the flux levels in the back iron and teeth of the machine to be accurately determined. Because of the unusual structure of the 


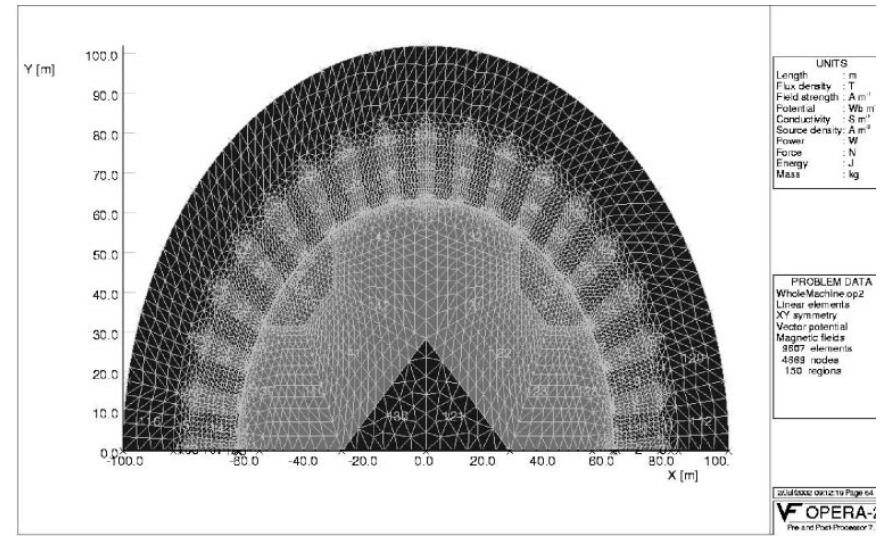

Fig. 12. FE model of the BDFRM.

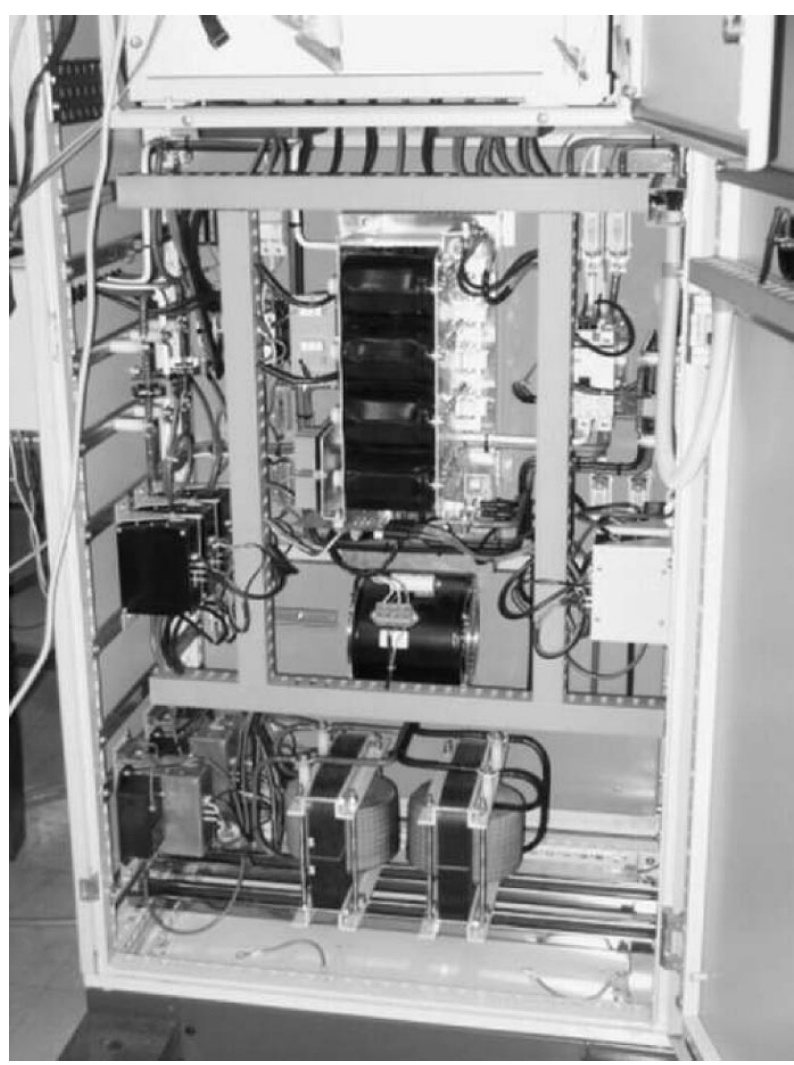

Fig. 13. Three-phase 38-kW 415-Vac insulated-gate-bipolar-transistor (IGBT)-based inverter to be used for the testing.

BDFRM the normal quarter machine symmetry cannot be used, and instead a half machine model has to be developed. Fig. 12 shows the FE model.

The power electronics and control computer for the experimental system already exist. The controller is based on a high-performance TMS6701 floating-point digital signal processor. Several custom-designed Altera electrically programmable logic devices (EPLDs) are used to control the sampling system and the firing of the inverter power devices. Figs. 13 and 14 show the power electronics and the control board.

The machine to be tested will be mounted on a dynamometer (Fig. 15) so that precise reading of torque, output power, and input power can be made and, therefore, the machine efficiency

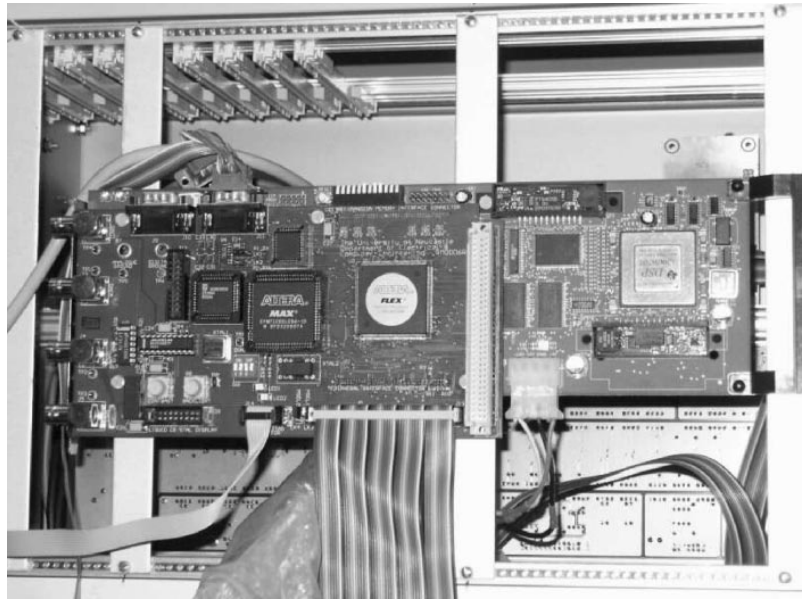

Fig. 14. TMS6701-DSP-based control board for the experimental system.

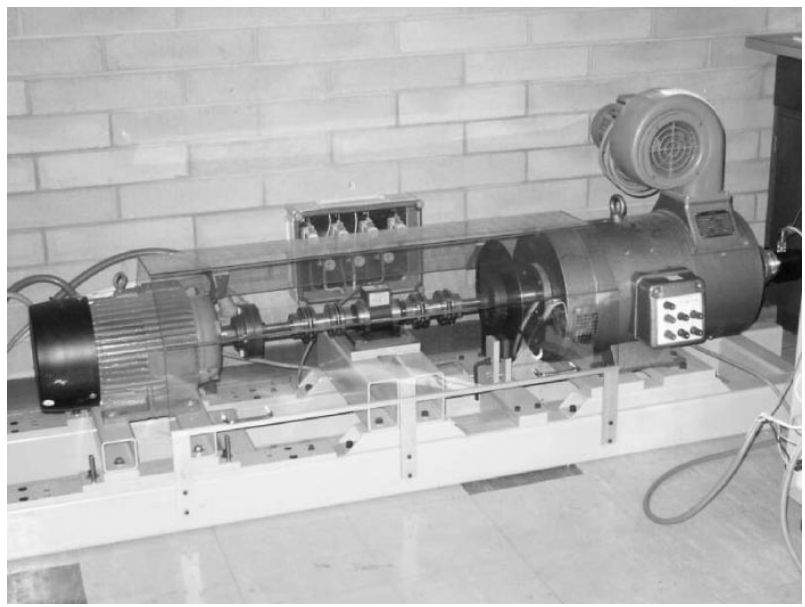

Fig. 15. Dynamometer to be used for the testing.

determined. In addition, the performance of the scalar and vector control strategies will be evaluated using this rig, and the results compared with the theory.

\section{CONCLUSIONS}

This paper has investigated different control strategies and aspects of both vector and scalar control of the BDFRM in the light of its potential applications: wind turbines and large pumps. While the work presented is largely theoretical in nature and has considered an ideal machine, a number of important relationships and preliminary results, which can serve as a basis for control development and implementation in real machines, have been derived.

Another significant contribution of the paper lies in the discussion of tradeoffs between the machine performance and size of the supply inverter. It is expected that the economic benefits of these compromises will ultimately decide the BDFRM's future.

The development of two BDFRM prototypes and the corresponding test systems for experimental verification of the considered control strategies are currently in progress at the University of Newcastle, Callaghan, Australia, and the University 
of Northumbria, Newcastle upon Tyne, U.K. The main components of the former drive system have been described in the paper.

\section{REFERENCES}

[1] Y. Liao, "Design of a brushless doubly-fed induction motor for adjustable speed drive applications," in Conf. Rec. IEEE-IAS Annu. Meeting, San Diego, CA, Oct. 1996, pp. 850-855.

[2] R. E. Betz and M. G. Jovanović, "The brushless doubly fed reluctance machine and the synchronous reluctance machine-A comparison," IEEE Trans. Ind. Applicat., vol. 36, pp. 1103-1110, July/Aug. 2000.

[3] L. Xu and Y. Tang, "A novel wind-power generating system using field orientation controlled doubly-excited brushless reluctance machine," in Conf. Rec. IEEE-IAS Anпи. Meeting, Houston, TX, Oct. 1992, pp. 408-413.

[4] C. S. Brune, R. Spee, and A. K. Wallace, "Experimental evaluation of a variable-speed doubly-fed wind-power generation system," IEEE Trans. Ind. Applicat., vol. 30, pp. 648-655, May/June 1994.

[5] S. Bhowmik, R. Spee, and J. H. R. Enslin, "Performance optimization for doubly fed wind power generation systems," IEEE Trans. Ind. Applicat., vol. 35, pp. 949-958, July/Aug. 1999.

[6] B. Gorti, D. Zhou, R. Spée, G. Alexander, and A. Wallace, "Development of a brushless doubly-fed machine for a limited speed pump drive in a waste water treatment plant," in Conf. Rec. IEEE-IAS Annu. Meeting, Denver, CO, Oct. 1994, pp. 523-529.

[7] M. S. Boger, A. K. Wallace, and R. Spee, "Investigation of appropriate pole number combinations for brushless doubly fed machines applied to pump drives," IEEE Trans. Ind. Applicat., vol. 32, pp. 189-194, Jan./Feb. 1996.

[8] O. Ojo and Z. Wu, "Synchronous operation of a dual-winding reluctance generator," IEEE Trans. Energy Conversion, vol. 12, pp. 357-362, Dec. 1997.

[9] S. Williamson, A. Ferreira, and A. Wallace, "Generalized theory of the brushless doubly-fed machine. Part 1: Analysis," Proc. IEE-Elect. Power Applicat., vol. 144, pp. 111-122, Mar. 1997.

[10] F. Wang, F. Zhang, and L. Xu, "Parameter and performance comparison of doubly-fed brushless machine with cage and reluctance rotors," IEEE Trans. Ind. Applicat., vol. 38, pp. 1237-1243, Sept./Oct. 2002.

[11] L. Xu, L. Zhen, and E. Kim, "Field-orientation control of a doubly excited brushless reluctance machine," IEEE Trans. Ind. Applicat., vol. 34, pp. 148-155, Jan./Feb. 1998.

[12] D. Zhou, R. Spee, and G. C. Alexander, "Experimental evaluation of a rotor flux oriented control algorithm for brushless doubly-fed machines," IEEE Trans. Power Electron., vol. 12, pp. 72-78, Jan. 1997.

[13] R. Li, R. Spee, A. K. Wallace, and G. C. Alexander, "Synchronous drive performance of brushless doubly-fed motors," IEEE Trans. Ind. Applicat., vol. 30, pp. 963-970, July/Aug. 1994.

[14] R. E. Betz and M. G. Jovanović, "Control aspects of brushless doubly fed reluctance machines," in Proc. European Power Electronics Conf., Lausanne, Switzerland, Sept. 1999.

[15] F. Liang, L. Xu, and T. Lipo, " $D-q$ analysis of a variable speed doubly AC excited reluctance motor," Elect. Mach. Power Syst., vol. 19, pp. 125-138, Mar. 1991

[16] M. G. Jovanović and R. E. Betz, "Power factor control using brushless doubly fed reluctance machines," in Conf. Rec. IEEE-IAS Annu. Meeting, vol. 1, Rome, Italy, Oct. 2000, pp. 523-530.

[17] Y. Liao, L. Xu, and L. Zhen, "Design of a doubly-fed reluctance motor for adjustable speed drives," IEEE Trans. Ind. Applicat., vol. 32, pp. 1195-1203, Sept./Oct. 1996.
[18] Y. Liao and C. Sun, "A novel position sensorless control scheme for doubly fed reluctance motor drives," IEEE Trans. Ind. Applicat., vol. 30, pp. 1210-1218, Sept./Oct. 1994.

[19] L. Xu and W. Cheng, "Torque and reactive power control of a doubly fed induction machine by position sensorless scheme," IEEE Trans. Ind. Applicat., vol. 31, pp. 636-642, May/June 1995.

[20] Y. Tang and L. Xu, "A flexible active and reactive power control strategy for a variable speed constant frequency generating system," IEEE Trans. Power Electron., vol. 10, pp. 472-478, July 1995.

[21] L. Xu and F. Wang, "Comparative study of magnetic coupling for a doubly fed brushless machine with reluctance and cage rotors," in Conf. Rec. IEEE-IAS Annu. Meeting, New Orleans, LA, Oct. 1997, pp. 326-332.

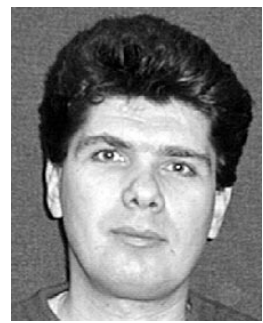

Milutin G. Jovanović (M'97) received the Dipl.Eng and M.E.E. degrees from the University of Belgrade, Belgrade, Yugoslavia, in 1987 and 1991, respectively, and the Ph.D. degree from the University of Newcastle, Callaghan, Australia, in 1997.

$\mathrm{He}$ is currently a Senior Lecturer in the School of Engineering and Technology, Northumbria University, Newcastle upon Tyne, U.K. His main interests are in the areas of electrical machines and drives, power electronics, and renewable energy systems.

Dr. Jovanović is a member of the Industrial Drives and the Electric Machines Committees of the IEEE Industry Applications Society.

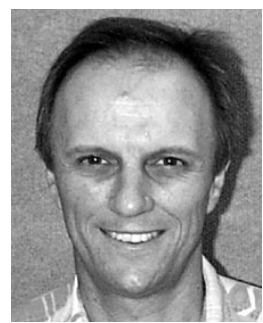

Robert E. Betz (M'92) received the B.E., M.E., and $\mathrm{Ph} . \mathrm{D}$. degrees from the University of Newcastle, Callaghan, Australia, in 1979, 1982, and 1984, respectively.

He is currently an Associate Professor and Head of the School of Electrical Engineering and Computer Science, University of Newcastle. His major interests are electrical machine drives, real-time operating systems, and industrial electronics. He was a Senior Research Fellow at the University of Glasgow, U.K. (1990-1991), and the Danfoss Visiting Professor at Aalborg University, Denmark (1998).

Dr. Betz is a member of the Industrial Drives and the Electric Machines Committees of the IEEE Industry Applications Society.

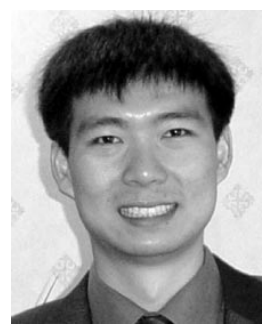

Jian Yu received the B.E. degree from Harbin Institute of Technology, Harbin, China, in 1998, and the M.Sc. degree from Newcastle University, Newcastle upon Tyne, U.K., in 2000. He is currently working toward the Ph.D. degree in the School of Engineering and Technology, Northumbria University, Newcastle upon Tyne, U.K

He is currently working on control of brushless doubly fed reluctance machines. His main interests are electric drives, power electronics, and wind power generation.

Mr. Yu is an associate member of the Institution of Electrical Engineers, U.K. 